\title{
Social Work Practice During COVID-19: Client Needs and Boundary Challenges
}

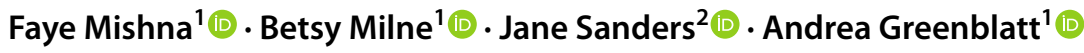

Accepted: 25 October 2021 / Published online: 5 November 2021

(c) The Author(s), under exclusive licence to Springer Nature Switzerland AG 2021

\begin{abstract}
While information and communication technologies (ICTs) permeated social work practice long before the onset of COVID19 , the abrupt need to close non-essential workplaces resulted in an unparalleled incorporation of digital technology into practice across the globe. The onset of COVID-19 occurred during phase two of research in which we were investigating social workers' informal use of ICT with clients. Prior to COVID-19, we were conducting interviews with practitioners and clients from four agencies serving diverse client populations in a large city in Canada. With the onset of COVID-19, we adapted to the COVID-19 context and amended the questions to investigate ICT use during the pandemic. In addition, with ethics approval, we conducted second interviews with practitioners interviewed prior to COVID-19 with a revised guide to address the pandemic context; and we continued to recruit and interview practitioners and clients using an amended interview guide incorporating pandemic-related questions. The sample comprised 27 practitioners and 22 clients. Eleven practitioners participated in interviews prior to and during COVID-19. Analysis of transcribed interviews revealed that the COVID-19 context had led to a paradigm shift in practitioners' ICT use, with two key themes identified: (1) boundary challenges and (2) clients' diverging ICT needs. We discuss these themes and present implications for policy and practice in a post-COVID-19 world.
\end{abstract}

Keywords Information and communication technology during COVID-19 - Social work practice during COVID-19 . Boundaries using technology in social work · COVID-19 and client accessibility $\cdot$ Equity in social work practice

\section{Introduction}

Information and communication technologies (ICTs) entered social work practice long before the onset of COVID-19. ICTs include mobile devices, computer hardware/software, and other communication media. In response to COVID19 , practitioners were required to quickly transition to ICTs to replace face-to-face services, without adequate training or support (Canady, 2020; Doorn et al., 2020; Razai et al., 2020; Walter-McCabe, 2020).

The purpose of the current study, which was underway at the onset of COVID-19, was to investigate social workers' informal ICT use with clients in Canada (Mishna et al., 2021a,

Faye Mishna

f.mishna@utoronto.ca

1 Factor-Inwentash Faculty of Social Work, University of Toronto, 246 Bloor St W, Toronto, ON M5S 1V4, Canada

2 Present Address: School of Social Work, King's University College at Western University, London, ON, Canada b). Recognizing the context of COVID-19, we amended the questions to investigate ICT use during the pandemic. The original guiding research questions examined the ways social workers used informal ICTs with clients and the impact of this use on face-to-face practice. We amended the research questions to investigate the ways social workers used ICTs during this global pandemic and the impact of this use on practice.

\section{ICT Use in Practice}

Prior to COVID-19, ICT use in social work had become a "significant component of the contemporary clinical landscape" (Reamer, 2015, p. 123). ICTs had permeated practice in three ways (Mishna et al., 2017): formal online ICTs, which are standalone programs (e.g., e-counseling/therapy) (Chan \& Holosko, 2016) whereby secure ICT communication is the single mode of treatment (Luxton et al., 2011); formal blended ICTs, which combine ICT and face-to-face components (e.g., text message monitoring) (Anthony et al., 2019); 
and informal ICTs, in which unplanned ICT use occurs in conjunction with face-to-face practice (Mishna et al., 2012).

Formal and blended online therapies are as effective as face-to-face therapy (Chan \& Holosko, 2016; Sucala et al., 2013). Ethical concerns related to social workers' informal ICT use include boundary issues and "friend requests" on social media (Ryan \& Garrett, 2018).

\section{COVID-19 Context}

The pandemic brought an abrupt need to close non-essential workplaces (Galea et al., 2020), which led to an unparalleled incorporation of ICTs into practice. Psychologists' delivery of tele-mental health services increased from $7 \%$ to over $85 \%$ during the pandemic (Pierce et al., 2020), and clients' use of telehealth increased from 10 to $90 \%$ (Canady, 2020). This dramatic change represented a paradigm shift, as previous distinctions between formal and informal ICT use came into question (Mishna et al., 2020).

Inclusion of ICTs has had variable effects. ICTs have allowed practitioners to provide continuity of care (Gentry et al., 2021; Waller et al., 2020), and maintain the therapeutic relationship during COVID-19 (McKenny et al., 2021; Moring et al., 2020). ICTs removed client barriers related to transportation, work commitments, and childcare (Hopkins \& Pedwell, 2021), and improved client attendance and engagement (McKenny et al., 2021). Many practitioners intend to continue providing digital services to some degree beyond COVID-19 (Gentry et al., 2021).

Alongside benefits, ethical concerns associated with remote services have been identified.

Practitioners have experienced increased blurring of boundaries and challenges managing private and work lives (Hopkins \& Pedwell, 2021; Liberati et al., 2021; Ross et al., 2021). The pandemic has exacerbated existing inequities by sharpening the "digital divide" among clients (Farkas \& Romaniuk, 2020, p. 1). Clients face barriers to remote services due to matters such as poverty/financial, privacy, and childcare issues, rural settings, lack of technology literacy, psychiatric diagnoses, and age (Canady, 2020; Liberati et al., 2021; McKenny et al., 2021; Perrin et al., 2020; Pierce et al, 2020; Razai et al., 2020; Simpson et al., 2021; Wells et al., 2020). In this article, we provide a unique analysis of practitioners' and clients' perspectives before and after the onset of COVID-19.

\section{Theoretical Framework}

Ecological Systems Theory situates individuals in their social and environmental contexts, recognizing the interconnected factors that influence wellbeing (Bronfenbrenner, 1979). Expanding the ecological systems framework to incorporate ICTs increases our understanding that individuals are both influenced by and influence all levels of their environments (Johnson, 2010; Nesi, 2018). As ICTs affect all aspects of human interaction, it is critical to understand the implications of ICTs (Perron et al., 2010). The Technology Acceptance Model enhances understanding of ICT use by demonstrating that practitioners and clients use ICTs based on their perceived usefulness and ease of use (Bullock \& Colvin, 2015; Venkatesh \& Davis, 2000). The shift to working remotely amid COVID-19 is an unprecedented example of the influence of societal context on ICT uptake. Integrating these theoretical frameworks into social work's foundational and ongoing education marks an important move to treating ICTs as a core component of practice.

\section{Methods}

\section{The Current Study}

The current study is the second of two sequential phases in a mixed-methods study. Phase one entailed an online survey administered to practitioners in Canada, the USA, Israel, and the UK, which explored informal ICT use in face-to-face practice (Mishna et al., 2021a, b). Informed by the survey data, the current study (phase two) began in April 2019, which involved semi-structured interviews with practitioners and clients in a large city in Canada.

Adapting to the pandemic, we conducted second interviews with practitioners interviewed prior to COVID-19, using a revised guide to address the pandemic context; and we continued to recruit and interview practitioners and clients using an amended interview guide incorporating pandemic-related questions. We received approval for the amendment from the University's Research Ethics Board (Mishna et al., 2020).

\section{Sample}

Practitioners and clients were recruited from four agencies in a large Canadian city. Agencies were selected to represent maximum variability through a range of services provided to diverse client populations of youth and adults. Initial eligibility criteria included: (1) registration with the regulatory body or holding a BSW/MSW, and (2) involved in direct face-to-face practice. Based on feedback from participating agencies, we broadened eligibility to include other agency practitioners (i.e., Mental Health Workers, Youth Workers, Traditional Elders). Five practitioners recruited during COVID-19 met the new criteria. Clients were required to be 16 years and older.

The sample comprised 27 practitioners and 22 clients. Most practitioners were female $(n=24)$ with two male practitioners, and 1 non-binary practitioner. Practitioners were 
between 24 and 61 years of age, and worked in diverse areas (e.g., addiction, anti-human trafficking, child welfare, violence against women, seniors, children/youth, and 2SLG$\mathrm{BTQ}+)$. The majority had practiced for 6 to 10 years $(n=8)$, seven practiced for 1 to 5 years, six for less than 1 year, and four participants practiced for 11 plus years. Clients (male $=7$, female $=11$ ) were between 17 and 60 years. The majority reported meeting with their practitioner between 1 and 2 years $(n=9)$, followed by over 3 years $(n=5)$, and less than 1 year $(n=4)$.

\section{Recruitment}

For phase two recruitment (April 2019), agency administrators emailed flyers describing the study, and research assistants set up tables in agencies and attended staff meetings. To recruit new participants during COVID-19 (March 2020), administrators promoted the study through email and in virtual staff meetings. Participants were offered a gift card, valued up to $\$ 25$. To recruit practitioners for second interviews during COVID-19, the Research Coordinator sent emails to practitioners who had participated in interviews prior to COVID-19. To recruit clients, administrators distributed flyers, and practitioners discussed the study in sessions. After the onset of COVID-19, administrators and practitioners advertised the study by email or during remote sessions and provided the Research Coordinator's contact information. Clients who contacted the Research Coordinator were assured that staff would not know whether they participated.

\section{Data Collection and Analysis}

Before COVID-19 (April 2019 to mid-March 2020), trained research assistants conducted 30 interviews (14 practitioners, 16 clients). During COVID-19 (mid-March to September 2020), 30 interviews were conducted. Of these interviews conducted during COVID-19, 19 were with new participants (13 practitioners, 6 clients), and 11 were second interviews with practitioners who were interviewed before COVID-19. Second interviews were conducted shortly after the COVID-19 lockdown began.

Pre-COVID interviews were 1-2 hours in length and were conducted in-person or by phone. Interviews conducted with new participants during COVID-19 used a revised, pandemic-related guide, and lasted approximately $2 \mathrm{~h}$; practitioners and clients were asked about their ICT use before and after the onset of COVID-19. Likewise, second interviews with practitioners during COVID-19 used a new interview guide exploring the impact of COVID-19 on ICT use, as well as the opportunities and challenges introduced by the pandemic. Second interviews lasted approximately $30-45 \mathrm{~min}$. With participant consent, interviews were audio-recorded, and professionally transcribed. NVivo software was utilized to organize data.

We conducted an inductive thematic analysis using a semantic approach, in which themes were identified within the explicit meanings of the data, i.e., what a participant said (Braun \& Clarke, 2006). Following Braun and Clarke's (2006) six step approach to engaging with text-based data, we read and re-read the transcripts. Using NVivo, two researchers coded interesting features of the data, and collated codes into potential themes. The research team reviewed, defined, and named the themes. An initial thematic map was created and reworked until the themes captured the coded data. We used strategies to enhance rigor and trustworthiness, including an audit trail of decisions, peer debriefing, and researcher triangulation (Nowell et al., 2017).

\section{Results}

Analysis of practitioners and clients' perspectives of service delivery signaled a paradigm shift in ICT use during COVID-19 (Mishna et al., 2020). Two key themes were identified: (1) boundary challenges and (2) clients' diverging ICT needs. Each theme is divided into pre- and during COVID19 responses.

\section{Theme One: Boundaries}

\section{Pre-COVID-19}

Most clients acknowledged contacting practitioners outside of business hours. A client remarked, "[When] I'm sending an email, I'll send it whenever. There's no boundary around when to send it." Clients stated however, that they did not expect an immediate response. Rather, most expected a response the next business day. According to clients, "at night they are off"; and "it's a 9:00 to 5:00 job." Clients commented that practitioners often met their expectations. One client noted, "If I email her after work hours, the next morning she answers me." Most clients considered the prompt response important, with several stating it made them feel cared for.

Practitioners in the four agencies described setting clear boundaries with clients and avoiding communication outside of business hours. While practitioners described setting boundaries regarding their ICT response times, managing clients' expectations required ongoing effort. One practitioner attributed her difficulty to clients who "wouldn't respect 9:00 to 5:00, Monday to Friday." Several practitioners found that shifting to a work cellphone helped maintain boundaries, whereas those without a work cellphone articulated developing strategies to separate their work and 
personal lives. One practitioner explained that while they quickly drafted responses to clients, they delayed sending the emails, to avoid giving the impression of being available outside of business hours. Another practitioner relayed that, "to take a break" on vacation, they delete their cellphone's email App. Despite efforts to maintain boundaries, many practitioners responded to clients' ICT communication outside of business hours, partly due to feeling pressured to respond. Some felt conflicted between their desire to respond to a client and their determination to maintain boundaries. Several noted the effects of such struggles on their wellbeing.

\section{During COVID-19}

Like pre-COVID-19, clients acknowledged contacting practitioners outside of business hours. One client noted that their practitioner's availability was especially helpful during COVID-19: "my schedule is so off, so to be able to email someone at, say 4:00 in the morning, and know that when I wake up, I will have an email, is great." While the client conveyed not expecting an immediate response, the prompt response was clearly meaningful. Some clients observed a difference during COVID-19, stating that practitioners often responded outside of traditional business hours, which clients attributed to COVID-19, "because she's probably at home."

Challenges in maintaining boundaries intensified during COVID-19. Several practitioners believed clients assumed they had greater flexibility. One practitioner stated, "some clients know I'm working from home, so they don't understand why I can't just write back all the time." Another practitioner explained that despite repeatedly explaining that she could not respond on the weekend, a client countered, "you're at home, this is your cell phone, why can't you answer?" When asked about such issues before COVID-19, a practitioner responded, "It was a lot clearer for people to understand, 'she's in the office 9:00 to 5:00, Monday to Friday'. That's been made blurrier."

Several practitioners changed their habits during the pandemic, and became, "more prone to check emails outside of work hours now that I'm working from home and even respond to emails outside of work hours." One practitioner observed that, due to her agency's loosened ICT restrictions, she checked more messages after business hours. Seeing messages, especially if urgent, created pressure to respond: "If I see [the messages], I cannot un-see them." Loosening of ICT restrictions was a common trend across all agencies.

Practitioners reported a lack of agency guidance regarding maintaining boundaries. One practitioner described mixed directives during COVID-19, whereby, "the message I receive from management is that if I saw it, I need to respond. But they highlight I shouldn't see it. So, it's contradictory and brings unnecessary stress." Another practitioner stated that while their agency provided "reminders that it's harder to draw a line now between work time and home time..., it's on us to set those parameters for our clients."

As in the pre-COVID-19 interviews, some practitioners felt their wellbeing was affected. One practitioner explained that not responding to messages created "what-if" scenarios, and "anxiousness" that they were missing something or "doing a very bad job."

\section{Theme Two: Clients' Diverging ICT Needs}

\section{Pre-COVID-19}

Clients revealed varying needs and preferences. Some preferred ICT communication, which they considered "more comfortable and useful." One client elaborated that ICT communication allowed them to hide their face when talking about sensitive issues. Another client attributed their preference for ICTs to being able to contact their social worker whenever they did not "feel good." Other clients, however, found ICTs challenging. One client explained, "you cannot have the feeling of being felt," and another characterized speaking as "only maybe $20 \%$ of communication. It's the tone, body language, demeanour." Difficulty accessing and using ICTs was identified as a barrier. One client commented, "I' $m$ older, so I'm not used to all of this technology."

Practitioners likewise identified diverging ICT needs among clients, with ICTs both fostering access for certain populations and revealing inequitable access among clients. A practitioner considered texting effective with LGBTQ + youth, which they found "simpler" to "say certain things writing it down, especially around fragile identities, queer identities." The practitioner attributed this to experiences of a "world not so accepting of variety, diversity," which aligns with research findings (Craig et al., 2021).

\section{During COVID-19}

Clients' varying ICT experiences became apparent during COVID-19. The transition to ICTs increased some clients' access to services, for example, clients in remote locations or struggling with mental health issues. Other clients, however, found that reliance on ICTs created barriers to accessing services. One client with anxiety explained, "the thing that got me outside regularly was my appointments, so the fact that I don't have these appointments, makes me stuck inside longer, which does affect my mental health." Another client noted that due to PTSD, they were more distracted during videocalls. Some felt uncomfortable due to privacy concerns whereas others considered in-person communication "more meaningful." 
Rather than engage remotely when COVID-19 measures came into effect, one client decided to wait until they could meet in person.

Similarly, practitioners observed that COVID-19 highlighted clients' divergent ICT needs. They observed that ICTs facilitated some clients' access to services. Several practitioners observed that transitioning to ICT communication improved their ability to communicate with younger clients. Text messaging was considered particularly useful in helping youth feel "safer" and "more comfortable." Referring to youth whose parents were not supportive of their therapy, practitioners noted that remote service made it easier for the youth to attend sessions. Practitioners described rural clients' enhanced access to treatment. One practitioner in an Indigenous agency explained that this transition allowed access for youth in foster care who live outside of the city, who previously were unable to attend programming: "we have drum circles we're now running, and culture nights, over Zoom, so it has enhanced [access], our children and youth are better able to connect with their culture which is positive." Some practitioners observed that shifting to virtual sessions during COVID19 benefited some clients with anxiety as they are "in the comfort of their home."

Practitioners observed that COVID-19 exacerbated existing barriers and affected the wellbeing of some clients. One practitioner stated, "clients who don't have Internet are definitely feeling a lot more isolated. They're not able to participate in a lot of the online hangouts." Another practitioner similarly commented, "I have some clients that don't have access to technology or the internet. I have some rural clients that are really struggling right now." Stressing that lack of digital literacy hindered access to services, a practitioner stated, "digital literacy is definitely a big thing where it's very difficult to provide instructions by phone in terms of how to send or set up email or other accounts." Some agencies and workers found ways to mitigate barriers, such as delivering prepaid phones to clients without ICT access and helping clients use new technologies.

\section{Discussion}

Due to the drastic restrictions to deter the COVID-19 virus, agencies and practitioners across the globe rapidly shifted from in-person to online treatment (Doorn et al., 2020; Razai et al., 2020; Walter-McCabe, 2020). Unique analysis exploring the experiences of clients and practitioners before and during COVID-19 revealed a paradigm shift. The two main themes comprised boundary challenges and clients' diverging ICT needs.

\section{Boundary Challenges}

Prior to and during COVID-19, clients regularly contacted practitioners outside of business hours (Mishna et al., 2020) and appreciated practitioners' prompt responses. During COVID-19, practitioners expressed feeling greater pressure to respond to ICT communication, which may be due to factors such as the changed context of service delivery and practitioners' consequent flexibility. In accommodating to the pandemic context, practitioners extended established boundaries. For example, as their practitioner offered sessions and emailed in the evening during COVID-19, one client believed the practitioner had a greater "window of opportunity" to respond to ICT communication. This corresponds with literature indicating that there is a greater likelihood of boundary issues associated with services offered after office hours, due to remote work during the pandemic (Barsky, 2020). Although an acute response to a crisis (Canady, 2020; Walter-McCabe, 2020), such adaptations could confound client expectations.

Flexibility in connecting with clients may enhance the therapeutic relationship and concurrently generate boundary challenges through more frequent and less formal content (Simpson et al., 2021). Despite claiming that they did not expect practitioners to respond beyond office hours, clients appreciated practitioners responding promptly to ICT communication. Several practitioners believed that clients assumed practitioners had greater flexibility because of working from home during COVID-19. Indirectly or directly therefore, clients' expectations appear to contribute to the increased pressure expressed by practitioners to respond beyond business hours. Fear for client safety and wellbeing was another factor that exerted pressure to respond. Some practitioners depicted struggling internally, feeling compelled both to respond to clients outside of business hours and to maintain the boundaries. The context of the pandemic and remote service complicated practitioners' ability to differentiate these alternatives. This finding corresponds to other findings that during COVID-19, social workers commonly reported "perceived or overt pressure 'to be available' to meet emergent and acute patient needs" (Ross et al., 2021, p. 17).

Practitioners reported feeling consistently affected by boundary difficulties both before and during COVID-19. A practitioner described pressure to respond outside of business hours as "morally triggering" because of the difficulty determining what was best for their client. This finding corresponds with the literature on "moral distress," whereby repeated ethical dilemmas can produce distress and burnout (Dean et al., 2020; Patterson et al., 2021). There has been increased moral distress during COVID-19 due to dramatic policy changes (Patterson et al., 2021) as well as ethical 
dilemmas, boundary uncertainty, isolation, and burnout (Patterson et al., 2021; Ross et al., 2021).

\section{Diverging ICT Needs of Clients}

A second key theme is the diversity of client needs and preferences regarding ICTs, intensified by the COVID-19 context. The transition to remote services improved some clients' access to services, while posing greater barriers for others. Practitioners and clients noted the enhanced access to services for certain client populations, including those in remote areas, LGBTQ + youth, and some clients with mental health issues such as anxiety. This corresponds with findings that clients with anxiety disorders often benefit from digital services which they experience as less overwhelming and threatening (Razai et al., 2020; Simpson et al., 2021). Attending sessions remotely can alleviate barriers related to stigma in accessing mental health services (Moring et al., 2020; Sansom-Daly \& Bradford, 2020; Weissman et al., 2020), as well as barriers to individuals in geographically remote areas with limited mental health resources or those with impeded mobility due to medical or emotional concerns (Canady, 2020; Stanley \& Markman, 2020; Weissman et al., 2020; Whaibeh et al., 2020).

In their survey with clinicians, Hopkins and Pedwell (2021) found that the shift to online services benefited clients with adequate technology access and digital literacy skills. In contrast, client populations lacking ICT access or digital literacy skills suffered. While gaps existed prior to COVID-19, the move to remote sessions emphasized inequities and clients' divergent ICT needs. As ICT communication reduced barriers to service for some clients (e.g., transportation, stigma) (Moreland et al., 2021), a critical challenge will be to maintain remote options beyond COVID-19. Concurrently, the barriers faced by clients in accessing digital services, due to issues such as lack of Internet, privacy, or digital literacy, highlight the challenge in developing policies and supports to provide clients equitable access to digital services.

\section{Limitations}

The study has several limitations. The small sample size, voluntary, and self-selected participation suggest the need to be cautious in generalizing findings to practitioners and clients. Furthermore, we did not gather information on participants' socioeconomic background. Nevertheless, the current study provides a unique opportunity to examine practitioners' ICT use with clients both prior to and during COVID-19. Moreover, the results are supported by the existing literature.

\section{Implications for Policy and Practice}

Due to the paradigm shift in ICT use, practitioners face more difficulties navigating boundaries with clients (Mishna et al., 2020). Analysis revealed several contributing factors including modified regulations to accommodate COVID-19, practitioners' internal as well as client pressure, and a lack of clear agency guidance. Once face-to-face practice resumes, it is likely that the greater incorporation of ICTs in social work practice will continue. The complex factors producing boundary challenges emphasize that practitioners require support and viable options to maintain boundaries, while ensuring that clients receive needed support. It will be important for agencies to implement clear policies regarding professional boundaries. In phase one of the study (survey of social workers' informal ICT use), a significant percentage of participants did not discuss their ICT use with supervisors or colleagues (Mishna et al., 2021a, b). This finding underscores that organizations must provide support for practitioners in maintaining professional boundaries and ensuring wellbeing, for example, providing work cellphones, as participants found this helped them keep work separate from their personal lives.

Notwithstanding the 2016 declaration by the United Nations General Assembly that Internet access constitutes a basic human right (Sanders \& Scanlon, 2021), our findings indicate that agencies and practitioners are faced with the challenge of reducing barriers to clients' access to digital services. The digital divide represents a social justice issue with regard to high-risk populations (Cox, 2020; Farkas \& Romaniuk, 2020; Wells et al., 2020). It is incumbent "upon social workers to help identify and advocate for communities who continue to experience the digital divide" (Sanders \& Scanlon, p. 140) beyond the pandemic (Walter-McCabe, 2020), and to advocate for agency and government policies that ensure ICTs are provided to all clients.

\section{Conclusion}

The COVID-19 context has fostered a unique opportunity to reflect on challenges that existed before and during COVID19 and that will persist beyond the pandemic. Rather than attempt to return to the way things operated previously, this is an opportunity to develop client-centered models of service delivery that enable more options of access. Concurrently, it is critical to develop policies and supports for practitioners to maintain boundaries and wellbeing.

Funding This work was supported by the Social Sciences and Humanities Research Council of Canada (Grant no. 435-2016-0600). 


\section{Declarations}

Conflict of Interest The authors declare no competing interests.

\section{References}

Anthony, N., Mokokwu, J., \& Alozie, O. (2019). Implementation of a text message to improve adherence to clinical and social service appointments. Journal of the International Association of Providers of AIDS Care, 18, 1-5. https://doi.org/10.1177/ 2325958219870166

Barsky, A. (2020). Ethical exceptions for social workers in light of the COVID-19 pandemic and physical distancing. The New Social Worker. Retrieved April 5th, 2020, from https://www.socialworker. com/feature-articles/ethics-articles/ethical-exceptions-socialworkers-in-light-of-covid-19-pandemic-physical-distancing/

Braun, V., \& Clarke, V. (2006). Using thematic analysis in psychology. Qualitative Research in Psychology, 3(2), 77-101. https://doi.org/ 10.1191/1478088706qp063oa

Bronfenbrenner, U. (1979). The ecology of human development: Experiments by nature and design. Harvard University Press.

Bullock, A., \& Colvin, A. (2015). Communication technology integration into social work practice. Advances in Social Work, 16(1), 1-14. https://doi.org/10.18060/18259

Canady, V. A. (2020). As MH workforce evolves during COVID-19, telehealth seen as new normal. Mental Health Weekly, 30(19), 1-4. https://doi.org/10.1002/mhw

Chan, C., \& Holosko, M. J. (2016). A review of information and communication technology enhanced social work interventions. Research on Social Work Practice, 26(1), 88-100. https://doi.org/ $10.1177 / 1049731515578884$

Cox, C. (2020). Older adults and Covid 19: Social justice, disparities, and social work practice. Journal of Gerontological Social Work, 63(6-7), 611-624. https://doi.org/10.1080/01634372.2020. 1808141

Craig, S. L., Lacono, G., Pascoe, R., \& Austin, A. (2021). Adapting clinical skills to telehealth: Applications of affirmative cognitivebehavioral therapy with LGBTQ+ youth. Clinical Social Work Journal. https://doi.org/10.1007/s10615-021-00796-x

Dean, W., Talbot, S. G., \& Caplan, A. (2020). Clarifying the language of clinician distress. JAMA: The Journal of the American Medical Association, 323(10), 923-924. https://doi.org/10.1001/jama. 2019.21576

Doorn, K. A., Békés, V., \& Prout, T. A. (2020). Grappling with our therapeutic relationship and professional self-doubt during COVID-19: Will we use video therapy again? Counselling Psychology Quarterly. https://doi.org/10.1080/09515070.2020.1773404

Farkas, K. J., \& Romaniuk, J. R. (2020). Social work, ethics and vulnerable groups in the time of coronavirus and Covid-19. Society Register, 4(2), 67-82. https://doi.org/10.14746/sr.2020.4.2.05

Galea, S., Merchant, R. M., \& Lurie, N. (2020). The mental health consequences of COVID-19 and physical distancing: The need for prevention and early intervention. JAMA Internal Medicine, 180(6), 817-818. https://doi.org/10.1001/jamainternmed.2020. 1562

Gentry, M. T., Puspitasari, A. J., McKean, A. J., Williams, M. D., Breitinger, S., Geske, J. R., Moore, K. M., Frye, M. A., \& Hilty, D. M. (2021). Clinician satisfaction with rapid adoption and implementation of telehealth services during the COVID-19 pandemic. Telemedicine and e-Health. https://doi.org/10.1089/tmj.2020.0575

Hopkins, L., \& Pedwell, G. (2021). The COVID PIVOT - Reorienting child and youth mental health care in the light of pandemic restrictions. Psychiatric Quarterly. https://doi.org/10. 1007/s11126-021-09909-8

Johnson, G. M. (2010). Internet use and child development: The techno-microsystem. Australian Journal of Educational \& Developmental Psychology, 10, 32-43.

Liberati, E., Richards, N., Parker, J., Willars, J., Scott, D., Boydell, N., Pinfold, V., Martin, G., Dixon-Woods, M., \& Jones, P. B. (2021). Remote care for mental health: Qualitative study with service users, carers and staff during the COVID-19 pandemic. British Medical Journal Open, 11, e049210. https://doi.org/10.1136/ bmjopen-2021-049210

Luxton, D. D., McCann, R. A., Bush, N. E., Mishkind, M. C., \& Reger, G. M. (2011). mHealth for mental health: Integrating smartphone technology in behavioral healthcare. Professional Psychology: Research and Practice, 42(6), 505-512. https://doi.org/10.1037/ a0024485

McKenny, R., Galloghly, E., Porter, C. M., \& Burbach, F. R. (2021). 'Living in a Zoom world': Survey mapping how COVID-19 is changing family therapy practice in the UK. Journal of Family Therapy, 43, 272-294. https://doi.org/10.1111/1467-6427.12332

Mishna, F., Bogo, M., Root, J., Sawyer, J., \& Khoury-kassabri, M. (2012). "It just crept in": The digital age and implications for social work practice. Clinical Social Work Journal, 40(3), 277286. https://doi.org/10.1007/s10615-012-0383-4

Mishna, F., Fantus, S., \& McInroy, L. (2017). Informal use of information and communication technology: Adjunct to traditional face-to-face social work practice. Clinical Social Work Journal, 49, 49-55.

Mishna, F., Milne, E., Bogo, M., \& Flores Pereira, L. (2020). Responding to COVID-19: New trends in social workers' use of information and communication Technology. Clinical Social Work Journal. https://doi.org/10.1007/s10615-020-00780-x

Mishna, F., Sanders, J., Daciuk, Milne, B., Fantus, J., Bogo, M., Fang, L., Greenblatt, A., Rosen, P., Khoury-Kassabri, M., Fang, L., \& Lefevre, M. (2021a). \#socialwork: An international study examining social workers' information and communication technology. British Journal of Social Work. https://doi.org/10.1093/bjsw/bcab066

Mishna, F., Sanders, J., Fantus, S., Fang, L., Greenblatt, A., \& Bogo, M. (2021b). \#socialwork: Informal Use of Information and Communication Technology. Clinical Social Work Journal, 49, 85-99. https://doi.org/10.1007/s10615-019-00729-9

Moreland, A., Guille, C., \& McCauley, J .L. (2021). Increased availability of telehealth mental health and substance abuse treatment for peripartum and postpartum women: A unique opportunity to increase telehealth treatment. Journal of Substance Abuse Treatment, 123. https://doi.org/10.1016/j.jsat.2020.108268

Moring, J. C., Dondanville, K. A., Fina, B. A., Hassija, C., Chard, K., Monson, C., LoSavio, S. T., Wells, S. Y., Morland, L. A., Kaysen, D., Galovski, T. E., \& Resick, P. A. (2020). Cognitive processing therapy for posttraumatic stress disorder via telehealth: Practical considerations during the COVID-19 pandemic. Journal of Traumatic Stress, 33, 371-379. https://doi.org/10.1002/jts.22544

Nesi, J., Choukas-Bradley, S., \& Prinstein, M. J. (2018). Transformation of adolescent peer relations in the social media context: Part 1: A theoretical framework and application to dyadic peer relationships. Clinical Child and Family Psychology Review, 21(3), 267-294. https://doi.org/10.1007/s10567-018-0261-x

Nowell, L. S., Norris, J. M., White, D. E., \& Moules, N. J. (2017). Thematic analysis: Striving to meet the trustworthiness criteria. International Journal of Qualitative Methods, 16, 1-13. 160940691773384. https://doi.org/10.1177/1609406917733847

Patterson, J. E., Edwards, T. M., Griffith, J. L., \& Wright, S. (2021). Moral distress of medical family therapists and their physician colleagues during the transition to COVID-19. Journal of Marital and Family Therapy, 47(2), 289-303. https://doi.org/10.1111/ jmft.12504 
Perron, B. E., Taylor, H. O., Glass, J. E., \& Margerum-Leys, J. (2010). Information and communication technologies in social work. Advances in Social Work, 11(2), 67-81. https://doi.org/10.18060/ 241

Perrin, P. B., Rybarczyk, B. D., Pierce, B. S., Jones, H. A., Shaffer, C., \& Islam, L. (2020). Rapid telepsychology deployment during the COVID-19 pandemic: A special issue commentary and lessons from primary care psychology training. Journal of Clinical Psychology, 76, 1173-1185. https://doi.org/10.1002/jclp.22969

Pierce, B. S., Perrin, P. B., Tyler, C. M., McKee, G. B. \& Watson, J. D. (2020). The COVID-19 telepsychology revolution: A national study of pandemic-based changes in U.S. mental health care delivery. American Psychologist, 76(1),14-25. https://doi.org/10.1037/ amp0000722

Razai, M. S., Oakeshott, P., Kankam, H., Galea, S., \& Stokes-Lampard, H. (2020). Mitigating the psychological effects of social isolation during the covid-19 pandemic. BMJ. https://doi.org/10.1136/bmj. m1904

Reamer, F. G. (2015). Clinical social work in a digital environment: Ethical and risk-management challenges. Clinical Social Work Journal, 43, 120-132. https://doi.org.myaccess.library.utoronto. $\mathrm{ca} /$ https://doi.org/10.1007/s10615-014-0495-0

Ross, A., Schneider, S., Muneton-Castano, Y. F., Al Caldas, A., \& Boskey, E. R. (2021). "You never stop being a social worker:" Experiences of pediatric hospital social workers during the acute phase of the COVID-19 pandemic. Social Work in Health Care, 60(1), 8-29. https://doi.org/10.1080/00981389.2021.1885565

Ryan, D., \& Garrett, P. M. (2018). Social work 'logged on': Contemporary dilemmas in an evolving 'techno-habitat'. European Journal of Social Work, 21(1), 32-44. https://doi.org/10.1080/13691457. 2016.1278520

Sanders, C. K., \& Scanlon, E. (2021). The digital divide is a human rights issue: Advancing social inclusion through social work advocacy. Journal of Human Rights and Social Work, 6, 130-143. https://doi.org/10.1007/s41134-020-00147-9

Sansom Daly, U. M., \& Bradford, N. (2020). Grappling with the "human" problem hiding behind the technology: Telehealth during and beyond COVID-19. Psycho Oncology, 29, 1404-1408. https://doi.org.myaccess.library.utoronto.ca/ https://doi.org/10. 1002/pon.5462

Simpson, S., Richardson, L., Pietrabissa, G., Castelnuovo, G., \& Reid, C. (2021). Videotherapy and therapeutic alliance in the age of COVID-19. Clinical Psychology \& Psychotherapy, 28, 409-421. https://doi.org/10.1002/cpp.2521
Stanley, S. M., \& Markman, H. J. (2020). Helping couples in the shadow of COVID-19. Family Process, 59, 937-955. https://doi. org.myaccess.library.utoronto.ca/https://doi.org/10.1111/famp. 12575

Sucala, M., Schnur, J. B., Brackman, E. H., Constantino, M. J., \& Montgomery, G. H. (2013). Clinicians' attitudes toward therapeutic alliance in E-Therapy. The Journal of General Psychology, 140(4), 282-293. https://doi.org/10.1080/00221309.2013.830590

Venkatesh, V., \& Davis, F. D. (2000). A theoretical extension of the technology acceptance model: Four longitudinal field studies. Management Science, 46(2), 186-204. https://doi.org/10.1287/ mnsc.46.2.186.11926

Waller, G., Pugh, M., Mulkens, S., Moore, E., Mountford, V. A., Carter, J., Wicksteed, A., Maharaj, A., Wade, T. D., Wisniewski, L., Farrell, N. R., Raykos, B., Jorgensen, S., Evans, J., Thomas, J. J., Osenk, I., Paddock, C., Bohrer, B., Anderson, K., \& Smit, V. (2020). Cognitive-behavioral therapy in the time of coronavirus: Clinician tips for working with eating disorders via telehealth when face-to-face meetings are not possible. The International Journal of Eating Disorders, 53(7), 1132-1141. https://doi.org/ 10.1002/eat.23289

Walter-McCabe, H. A. (2020). Coronavirus pandemic calls for an immediate social work response. Social Work in Public Health, 35(3), 69-72. https://doi.org.myaccess.library.utoronto.ca/https:// doi.org/10.1080/19371918.2020.1751533

Weissman, R. S., Bauer, S., \& Thomas, J. J. (2020). Access to evidence-based care for eating disorders during the COVID-19 crisis. International Journal of Eating Disorders, 53(5), 639-646. https://doi.org/10.1002/eat.23279

Wells, S. Y., Morland, L. A., Wilhite, E. R., Grubbs, K. M., Rauch, S. A., Acierno, R., \& McLean, C. P. (2020). Delivering prolonged exposure therapy via videoconferencing during the COVID-19 pandemic: An overview of the research and special considerations for providers. Journal of Traumatic Stress, 33, 380-390. https://doi. org.myaccess.library.utoronto.ca/https://doi.org/10.1002/jts.22573

Whaibeh, E., Mahmoud, H., \& Naal, H. (2020). Telemental health in the context of a pandemic: The COVID-19 experience. Current Treatment Options in Psychiatry, 7, 198-202. https://doi.org/10. 1007/s40501-020-00210-2

Publisher's Note Springer Nature remains neutral with regard to jurisdictional claims in published maps and institutional affiliations. 